\title{
PERCEPÇÃO DE PROFESSORES SOBRE O BULLYING \\ ENTRE CRIANÇAS E ADOLESCENTES. DIMENSÕES DO \\ FRACASSO ESCOLAR
}

$\begin{array}{cl}\text { Resumo } \\ \text { O artigo mostra como o projeto } \\ \text { "Escola que Protege" serviu de } \\ \text { base para debater o bullying } \\ \text { como dimensão do fracasso } \\ \text { Mniversidade Federal de São Paulo } & \text { escolar. Os Orticipantes revelaram uma } \\ & \text { compreensão baseada nas noções } \\ & \text { de exclusão, estigmatização e } \\ & \text { deterioração de identidade em } \\ & \text { ritos de intimidação. } \\ & \text { Palavras-chave: Professores; } \\ & \text { Escola; Bullying; Alunos; } \\ & \text { Pesquisa. }\end{array}$

${ }^{1}$ Professor Livre-Docente do

Departamento de Educação da Escola

de Filosofia, Letras e Ciências

Humanas da Unifesp

Olh@res, Guarulhos, v. 1, n. 2, p. 31-55, Novembro, 2013. 
TEACHER'S PERCEPTION ON BULLYING AMONG CHILDREN AND ADOLESCENTS. DIMENSIONS ABOUT SCHOOLING FAILURE.

\begin{abstract}
The article shows how the project "Protective Schools" offered the base to debate bullying as dimension of schooling failure. Teachers shared their understanding that ritual of intimidation is based on exclusion, stigmatization and deterioration of identity.
\end{abstract}

Key-words: Teachers; School; Bullying; Students; Research. 


\section{Introdução}

Fui convidado a emitir opinião sobre bullying e fracasso escolar e me deparei com um problema da grande proporção.

O pesquisador que tem por objeto de investigação vulnerabilidades de crianças e adolescentes, ou que esteja interessado em pesquisar infâncias e juventudes de forma geral, enfrenta dificuldades de monta quando chamado a emitir opinião sobre as práticas de bullying entre alunos.

A partir da década de 1990, poucas palavras foram apropriadas com tamanha variação de sentido. A delimitação do foco, ou seja, a indicação de que a opinião solicitada deveria incidir sobre alunos e cenários escolares nem sempre exerceu efeitos facilitadores para empreender análise a respeito.

Para analisar as relações palpáveis entre o chamado bullying e as experiências de fracasso escolar me foi necessário, antes, realizar um processo de organização analítica que me facultasse entender, primeiramente, o que não deve ser confundido com bullying.

Esse esforço de depuração precisou valer-se de uma dinâmica, algo inspirado na "apuração de sentidos" de Raymond Williams (2000), para chegar a um patamar de compreensão que não me deixasse preso ou aturdido com a profusão de sentidos que as personagens dos cenários escolares têm atribuídos à palavra bullying.

O universo heurístico de minha procura foi relativamente amplo e, justamente por isso, foi fundamental estabelecer a priori o que o bullying não é, ou não é exclusivamente, já que em inúmeras circunstâncias a palavra foi mobilizada pelos interlocutores da pesquisa que serviu de

Olh@res, Guarulhos, v. 1, n. 2, p. 31-55, Novembro, 2013. 
fundamento para este artigo para designar toda e qualquer manifestação de violência entre pares.

Interessado em produzir uma abordagem antropológica da questão, ou seja, convencido de que certo ritualismo e encadeamento simbólico poderiam ser identificados e compreendidos na dinâmica interna do fenômeno, adotei três procedimentos para delimitar as bases analíticas que o tema exige de mim.

O primeiro procedimento foi o de identificar os modos de apropriação da palavra entre professores para descrever episódios de violências entre pares nas escolas.

A seleção de fontes para essa análise sobre apropriação da palavra bullying valeu-se da rica base de informações proporcionada pelo Programa de Extensão denominado Escola que Protege: Interação Comunitária e Prevenção de Violências contra Crianças e Adolescentes.

Esse Programa, em andamento desde 2009, proporcionoume a experiência de dialogar com mais de mil professores das redes públicas de ensino das cidades de Guarulhos e São Paulo, sendo que em São Paulo a interação se dá com as redes municipal e estadual.

A base territorial do Programa abrange bairros expressivamente populosos como Água Chata, Bonsucesso, Cabuçu, Pimentas e Presidente Dutra em Guarulhos e Itaquera, Guayanazes, Cidade Tiradentes e São Matheus em São Paulo.

Como se percebe trata-se de uma base territorial periférica em ambas as cidades e que têm, em comum, o acentuado déficit de serviços públicos que caracteriza as bordas de nossas metrópoles (Deák e Schiffer, 1999). 
A dinâmica do Programa consiste em compartilhar experiências bem sucedidas de prevenção de violências contra crianças e adolescentes.

Em oficinas temáticas que utilizam a estrutura de diversos Centros de Educação Unificados (CEUs) ou que visitam escolas públicas, são oferecidos elementos conceituais para a compreensão da violência como fenômeno que se desdobra em múltiplas manifestações e que não se reduz às explicações monocausais .

Nessas situações é utilizada a estratégia da "escuta ativa". Esse procedimento consiste em recolher das perguntas e manifestações dos professores e demais participantes, palavras-chave com as quais se torna possível identificar as formas, através das quais, a violência contra a criança e o adolescente é percebida, é traduzida em gestos e é ressignificada.

Não me deparei com um único coletivo de professores e gestores que não se queixasse do bullying entre alunos.

Tornava-se necessário, então, organizar aquilo que Rosanvallon (1995) sugere ser uma "árvore de sentidos", ou seja, identificar as palavras para as quais convergem interpretações aparentemente desconexas.

O segundo procedimento foi o de participar de situações que favorecessem o registro documental alusivo ao bullying como, por exemplo, alguns Conselhos de Classe, alguns Conselhos de Escola e algumas reuniões com membros dos Conselhos Tutelares.

O terceiro procedimento, mais complexo e delicado, foi o de aproximação em relação a algumas crianças e adolescentes identificados como praticantes ou vítimas do bullying. Esse procedimento especificamente apresentou uma dificuldade própria, presumível, que será comentada adiante.

Olh@res, Guarulhos, v. 1, n. 2, p. 31-55, Novembro, 2013. 
Para levar a efeito a reflexão e a análise que organizam este artigo não é necessário mencionar instituições específicas, tampouco identificar pessoas. Esse expediente de "ocultação" é fundamental para a obtenção de informações e opiniões a respeito de situações que podem expor fragilidades expressivas.

\section{Na árvore de sentidos}

O tema bullying foi analisado no bojo de um projeto que não estava e não está direcionado única e exclusivamente para esse fim.

Tornou-se um tema por assim dizer inescapável. Em todas as situações nas quais o debate sobre vulnerabilidades infantis foi provocado a palavra bullying veio à tona.

Bullying é uma palavra da língua inglesa que sugere a presença do "valentão" e a prática do bullying diz respeito a processos de intimidação.

A profusão de sentidos verificável no uso da palavra fez lembrar uma intervenção de Ernesto Laclau, no final da década de 1970, situação em que as muitas ditaduras presentes na configuração geopolítica de então apresentavam sinais de enfraquecimento. Era um contexto que favorecia a multiplicação de diagnósticos sobre as raízes das tensões entre "povo e Estado".

Laclau mostrou perplexidade diante do abusivo e extenso uso da noção de populismo para esclarecer situações que a seu ver eram as mais diversas. Parecia-lhe que populismo era "usado para explicar tudo".

Quero recuperar a objeção que o autor apresentou ao "uso da palavra": 
Populismo é um conceito ao mesmo tempo evasivo e recorrente. Poucos conceitos têm sido tão amplamente usados na análise política contemporânea, embora bem poucos tenham sido definidos com menor precisão. Sabemos, intuitivamente, a que nos referimos quando qualificamos de populista a um movimento ou a uma ideologia. Porém, enfrentamos as maiores dificuldades para traduzir essa intuição em conceitos (Laclau, 1979, p. 149).

A advertência do autor nos convence que, se distinções mais pormenorizadas não forem efetuadas, ter-se-á que, desde o final do século XIX até o final do século XX, o populismo consolidou-se como imagem síntese capaz de reunir sob sua forma os eventos mais diversos como, por exemplo, o narodnichestvo russo, os pequenos proprietários norte-americanos, o varguismo, o peronismo, o janismo, o ademarismo e para alguns até o maoísmo ou o catolicismo popular da década de 1960 na América Latina (Cf. ibidem, 151-3).

Assim, o autor conclui que se entre eventos tão variados

(...) há pelo menos um elemento em comum, e que este elemento é o populismo, é evidente que sua especificidade terá que ser procurada fora, e não nas bases (...) desses movimentos que são totalmente diferentes (ibidem, p. 151, itálicos no original).

Se entre elementos tão variados presentes no cotidiano escolar relacionados ao enfrentamento, subjugação e intimidação entre pares o bullying é o dado comum que a todos esses eventos explica, na realidade se torna necessário perguntar se o bullying é, de fato,

Olh@res, Guarulhos, v. 1, n. 2, p. 31-55, Novembro, 2013. 
identificável, à medida que nos deparamos com um dilema sociológico de grandes proporções, ou seja, constatamos mais uma vez que aquilo que tudo explica, nada elucida. Assim, as dificuldades analíticas começaram à medida que o sentido atribuído ao bullying, de forma geral, dava à palavra um sentido derivado do uso intencionalmente voltado para a identificação da violência tout court.

Cabia fazer, como Laclau o fez em relação ao uso do conceito de populismo, uma verificação que ultrapassasse a simples identificação entre bullying e violência.

Mas mesmo esse esforço compreensivo exigiu um procedimento prévio no trato das palavras-chave. Se a palavra bullying estava, de forma generalizada, associada à violência fazia-se imprescindível registrar o quê aqueles professores denominavam violência.

Para além do que denota mais evidentemente a violência como agressões físicas e verbais, a palavra revelou-se parte substantiva das representações sobre a indisciplina e o desacato em relação à autoridade professoral.

Um professor relata que determinado aluno cometeu bullying ao gritar com ele, enquanto outro confirma que alguns, para além do desacato, acrescentam ameaças de retaliação como forma de reagir à reprimenda recebida em sala de aula.

À medida que o debate era reconduzido à razão inicial, ou seja, reconduzido à intenção primeira de compreender o complexo relacionamento entre alunos na escola, as discussões adquiriam maior consistência.

Nessas situações a intervenção de professores de língua estrangeira, especificamente de inglês, acrescentava aspectos muito interessantes ao debate. 
O mais expressivo, a meu ver, diz respeito às dúvidas que foram exteriorizadas e que cogitavam se as manifestações de assédio, perseguição, vitimização e atormentação já não estariam contidas no sentido que a palavra harassment adquiriu no universo da anglofonia.

A riqueza desse questionamento trouxe à dinâmica das oficinas um dado de orientação conceitual importante. Tornou possível compartilhar com o grupo que o questionamento apresentado pelo professor é muito relevante. No âmbito da sociologia francesa interessada no tema da violência nas escolas questão semelhante foi apresentada.

$\mathrm{Na}$ França, reflexão semelhante se dera ao redor da palavra racket, que indica a extorsão que alunos praticam em relação a pares "mais fracos" em busca de vantagens (Cf. Debarbieux, 1998).

A menção às palavras harassment e racket deu-se em situações de debate proporcionadas pelo Projeto Escola que Protege, em cujas manifestações dos docentes a palavra bullying era tomada, nos termos de Williams (2010) como palavra de "sentido aberto", cujo conteúdo se deve mais ao contexto intraescolar do que à etimologia.

A dinâmica de escuta ativa, própria da metodologia do Projeto Escola que Protege possibilitou, dessa forma, acrescentar ao trabalho um exercício de depuração conceitual em relação àquilo que Bonnafé-Schmitt (1997) chamou de "visão inflacionista de violência".

Em outras palavras, percebemos algo em conjunto. Se violência era o recurso para descrever toda turbulência provocada por alunos e se bullying era assimilado como se tivesse a mesma “inflação de sentidos", chegamos ao consenso de que fazia falta aos participantes uma

Olh@res, Guarulhos, v. 1, n. 2, p. 31-55, Novembro, 2013. 
teorização dedicada aos jogos de agressão física e verbal entre pares.

Mais uma vez foi necessário operar um deslocamento em direção às plataformas conceptuais que, na segunda metade do século XX, estabeleceram bases importantes para o estudo daquilo que Dubet (1994) denominou de situação privilegiada para compreender as lógicas da integração e da validação de interesses entre pares.

A criança sempre se depara com “eus disponíveis", para usar uma linguagem inspirada em Goffman (2004), mas já utilizada por Dubet e Martuccelli (1996).

A presunção de que cada um assumirá seu “eu escolar" e que terá um desempenho intelectual e comportamental correspondente ao que se espera desse eu, resulta na produção de incontáveis jogos de afirmação de identidade ou de "subjetivação", que na acepção desses autores quer dizer a construção de outro eu com base na assimilação positiva de características tidas pelos professores como negativas.

Um exemplo que imediatamente se apresentou entre professores quando entenderam essa afirmação foi o da presença de alunos em conflito com a lei que se tornam lideranças e são admirados por alguns à medida que "assumem" que não têm interesse mesmo no conjunto de regras que lhes são dispostas e que, "por vontade própria", se ocupam com a construção de outro eu, que não estava disponível na escola, mas que é trazido ao local justamente por esse novo ator, o outsider.

Essa situação é diferenciada das muitas cenas da moquerie que os franceses descrevem como escárnio e zombaria ou das cenas de mockery que os ingleses descrevem como a ridicularização, o arremedo e a insinuação de fraqueza.

Olh@res, Guarulhos, v. 1, n. 2, p. 31-55, Novembro, 2013. 
Nas escolas, a moquerie dos franceses tem sido apropriada para descrever as cenas em que alunos do "fundo da classe" proferem palavras de desprezo àqueles que assumem proximidade e cooperação para com os professores.

A mockerie dos ingleses tem sido apropriada para descrever cenas de diminuição de alunos com insinuações de que são bajuladores, afeminados ou tolos.

Ambas as palavras não têm conteúdo lexicográfico restrito à utilização em ambientes escolares, ou seja, são palavras de amplo uso nos idiomas inglês e francês.

O que os estudos de Dubet e Martuccelli mostram é que as palavras adquirem um conteúdo próprio no âmbito da cenografia escolar, cuja sala de aula é apenas um dos territórios da personificação de cada um e da produção de identidades consoante às demonstrações de força ou de fraqueza, de assunção ou de submissão de uns em relação aos outros.

Para além da associação randômica entre bullying e violências de toda sorte, quando buscamos identificar um denominador comum a todas as ações aleatoriamente associadas, três palavras ganharam relevo pela reiteração que tiveram em todas as escolas.

A ausência de clareza sobre o fenômeno bullying, a dificuldade em definir o que o fenômeno é, não inibiu a indicação do que certamente deveria organizar o conteúdo do "verbete bullying", caso fôssemos empreender esse trabalho. 
Os professores entendem que no bullying há sempre “exclusão", “estigmatização" e "deterioração da identidade". 1

Para analisar a consolidação de imagens como essas, que produziram efeitos organizadores na compreensão do bullying "dentro" do repertório analítico dos professores, passo a detalhar segundo procedimento adotado nesse processo.

Esse segundo passo consistiu em procurar nas decisões sobre o que registrar sobre incidentes disciplinares, os "vestígios e pistas", como diria Ginzburg (1989) para referir-se à formação de visões de mundo que aparentemente dão conexão ao que está desconexo, e registrar o momento em que pessoas têm uma elaboração conceitual que precede a apropriação do próprio conceito.

Ou seja, se violência é palavra insuficiente para dar conta da complexidade do fenômeno e se a escuta ativa estabeleceu um mínimo consenso de que as palavras exclusão, estigmatização e deterioração de identidade correspondiam ao sentido que as práticas de bullying adquiriam nas escolas dos participantes, tornou-se necessário procurar pelas narrativas que supostamente induziriam à documentação de tais situações.

\section{A palavra, sem transposições \\ O que está em curso neste artigo não é a avaliação do funcionamento de Conselhos e instâncias colegiadas das escolas.}

\footnotetext{
${ }^{1}$ É necessário registrar aqui minha intervenção na dinâmica dos trabalhos. Quando a intensa participação sinalizou um consenso coube a mim indicar que todos estavam se referindo à situações que na micro sociologia de Goffman são conceituadas como "estigma" e "deterioração de identidade", sem que isso signifique que os exemplos arrolados foram ajustados para adquirir compatibilidade com o que o autor em questão teorizou. A respeito conferir Goffman (1988).
}

Olh@ res, Guarulhos, v. 1, n. 2, p. 31-55, Novembro, 2013. 
As escolas públicas têm Conselhos de Escola, cada escola tem uma instância denominada Conselho de Classe e as funções de ambos não se confundem, nem se sobrepõem. Há variação regimental e situações particulares que diferenciam a governança escolar estadual da municipal, mas nada disso está em pauta aqui.

O fato é que a ação de alguns alunos contra outros se torna objeto de pauta e embora a referência ao bullying ocorra, não se verifica a transposição do argumento para a documentação. Ou seja, não há indicação para que conste em ata a prática de bullying, mas sim o desentendimento extremado e a agressividade exacerbada, com a devida caracterização com exemplos.

Destarte, predomina uma situação contraditória dentro da qual a palavra usada sem economia para referir-se quase que indistintamente à violência entre pares mantém-se na circunscrição do verbal, com menções esporádicas em registros que têm a função de pormenorizar acontecimentos dessa ordem.

Trata-se de uma apropriação trazida aos territórios da fala e guardada em seus domínios.

Não obstante, essas situações proporcionaram compreender as razões pelas quais se fixaram representações da exclusão, da estigmatização e da deterioração de identidades quando os professores debateram o bullying.

Ainda que as discussões não gerassem uma disposição a operar um "registro de bullying”, a elucidação entre pares sobre a dinâmica dos acontecimentos dava sinais de que alguns elementos se estabilizavam como constâncias, permanências, acumulações entre situações fragmentárias que eram reunidas como súmulas do bullying.

Olh@res, Guarulhos, v. 1, n. 2, p. 31-55, Novembro, 2013. 
O bullying se cristalizou como referência de "perseguição" empreendida por alunos genericamente descritos como "mais fortes" em relação a outros descritos também genericamente como "mais fracos".

A imprecisão caracteriza tais abordagens, mas há que considerar que a evocação da exclusão, quando se estabilizou, surpreendentemente, ofereceu parâmetros mais estáveis para discussão do problema.

Produzia-se consenso a respeito de que dada intercorrência fora manifestação de bullying com a reiterada indicação de que determinados atos, palavras e gestos resultaram na exclusão da vítima do convívio harmonioso com os demais.

A referência à exclusão tende a ser um recurso evasivo, não somente na escola, mas também nos mais diversos âmbitos da sociedade.

Vale a pena lembrar brevemente que autores como Martins (1997) puseram em dúvida o alcance epistemológico adstrito ao conceito e outros como Xiberras (1993) demonstraram que há uma profusão de teorias da exclusão em muitas matrizes sociológicas.

Brevemente é possível citar representações da exclusão nas obras de Émile Durkheim, Georg Simmel e Max Weber. Há teoria da exclusão nas chamadas "sociologias do desvio" cujo ícone de maior visibilidade é a Escola de Chicago.

Há também conexão com o tema da exclusão nos estudos sobre anomia, desvio e marginalidade. Da combinação desses temas desdobrou-se amplíssima rede de comentadores que se valeram das obras dos autores acima mencionados. 
Por fim, o tema é a razão de ser de quase todos os estudos sobre estratificação social, tornando-se uma espécie de pedagogia argumentativa da demonstração dos efeitos das estratificações.

Se a evocação desses autores gera uma advertência sobre os riscos presentes no uso da palavra exclusão como critério descritivo e definidor de situações micro e macroscópicas, a referência que os professores em questão fizeram à palavra como corolário de fatos ocorridos entre alunos, proporcionou reconhecer que a despeito dos riscos o uso se fazia necessário, conquanto se referisse a $\mathrm{um}$ sentido específico da noção de exclusão.

Que sentido específico seria esse?

Trata-se do sentido que Elias (2005) conferiu à palavra.

Elias percebeu que determinadas circunstâncias favorecem a produção de uma dicotomia ilusória entre um suposto ente coletivo (nós) e um suposto ente discriminado (ele ou eles).

Ainda que entre as partes pouco ou nenhuma diferença substantiva se apresente, a circunstância favorece a produção de um "estoque de aversões" que independentemente dos efeitos que seja capaz de surtir no outro e contra o outro, oferece "coesão para os que discriminam, excluem" (Cf. Elias, 2005, p. 100 e SS.).

A exclusão como dado de coesão interno ao rito de apontar para o outro se tornou um dos aspectos mais reveladores da percepção que os professores construíram sobre o tema.

Essa percepção, que embora fosse prejudicada pela identificação aleatória da palavra bullying com violências em geral, permitiu que o diálogo entre pares sugerisse 
uma das pistas mais férteis para compreender um fenômeno impregnado de complexidade.

O praticante do bullying, em todas as narrativas, nunca agiu sem contar com uma "plateia" que dava sustentação à intimidação do outro. Entre o praticante e os cúmplices por omissão estabelecia-se uma “coesão excludente", nos termos de Elias, contra alguém cuja vulnerabilidade tornava-se objeto de execração sustentada pelos vínculos entre o que faz e os que deixam fazer.

Dissipava-se um pouco das névoas da indefinição. O diálogo entre professores dava pertinência ao uso de um denso sentido de exclusão, ainda que a base de sustentação desse modo de ver sequer fosse mencionada, no caso Norbert Elias.

$\mathrm{Na}$ mesma trilha, a receptividade que os professores tiveram em relação ao conceito de "estigma" para tratar da questão, revelou um dado a meu ver digno de todos os elogios.

O tema bullying é objeto de crescente investida editorial e são abundantes as ofertas de diagnósticos que reduzem a complexidade da questão à denúncia patologizante de que temos entre nós "mentes perigosas".

Nos quatro anos de realização do Projeto Escola que protege, não detectei qualquer permeabilidade a esse tipo de argumentação e a indefinição que acompanha a apropriação da palavra bullying, não foi suficiente para que abordagens dessa natureza lograssem obter espaço, pelo menos no que tange às escolas abordadas.

O conjunto de exemplos que permitiu a utilização do conceito de estigma nas práticas de bullying apresentou situações nas quais o agredido foi descrito como alguém que se torna "desacreditado" (cf. Goffmann 1988, p. 51).

Olh@res, Guarulhos, v. 1, n. 2, p. 31-55, Novembro, 2013. 
E a referência ao conceito de estigma ficou ainda mais pertinente quando os exemplos utilizados para indicar a situação de "um desacreditado" invariavelmente chegavam à mesma conclusão que Goffman chegou, a de que "o desacreditado volta sempre como desacreditável” (ibidem).

A fragilidade da pessoa submetida a rituais de intimidação e humilhação pública enseja um círculo vicioso no qual pontos vulneráveis são explorados para indicar a impossibilidade do padecente de escapar das mãos do agente e, na sequência, se espalha uma percepção de que aquele padecente é, per se, uma pessoa incapaz de romper qualquer cerco de intimidação. Torna-se um intimidado intimidável diante de todos e por qualquer um.

Essa soma de perspectivas torna a percepção da deterioração da identidade, argumento proveniente do mesmo Goffman (1988 e 2010), praticamente uma consequência lógica de outra percepção que os professores desenvolveram, segundo a qual, os pontos vulneráveis ficam tão expostos que, em decorrência, os adjetivos recorrentes aplicados à pessoa tornam-se descritores "do que é o outro"; em outras palavras tornam-se a sua substância.

\section{Fragmentos da proximidade}

Não seria possível emitir opinião a respeito sem um mergulho prévio nas águas escuras e profundas da experiência em si, ou seja, sem conhecer de perto algumas crianças e adolescentes que foram identificados como vítimas de bullying nas escolas.

Ao início mencionei que esse procedimento apresentava uma dificuldade peculiar.

Cabe agora abordá-la, ainda que brevemente.

Olh@res, Guarulhos, v. 1, n. 2, p. 31-55, Novembro, 2013. 
Algumas situações ganharam contornos dramáticos e, por isso, a intervenção institucional não só interrompeu processos de intimidação em andamento como geraram condições para que os agressores assumissem a responsabilidade por suas condutas.

A peculiaridade mencionada diz respeito à ausência de menção ao bullying por parte de agentes e padecentes das situações descritas a posteriori como exemplares das práticas de intimidação.

As ações não foram denunciadas como bullying, interrompidas porque se tratava de bullying e punidas porque reconhecidas como bullying. Os pais foram comunicados dos excessos e as providências disciplinares foram tomadas sem que a palavra fosse considerada necessária.

Porém, a rememoração de cada ocorrido foi pautada pela disponibilidade a narrar episódios de bullying.

Do que se trata, afinal?

É necessário também trazer a este artigo uma questão relacionada à ética etnográfica. As incursões etnográficas pela escola proporcionam ângulos privilegiados para observar o cotidiano escolar por dentro (Woods, 2000). Esse adentrar nos domínios do microscópico favorece encontrar um ponto de observação em que as práticas de bullying possam ser percebidas, anotadas e analisadas.

São situações que sugerem adotar um pouco da postura que William Foote White propôs em seu clássico Sociedade de esquina.

Identificar uma "esquina estratégica" para perceber a produção de "atitudes desviantes" (Cf. White, 2008) pode ser um recurso produtivo no processo de apreender a os rituais de integração e desintegração que revelam, como 
sugere Becker (2008), a presença de outsiders em qualquer plano, não somente na relação previsível entre interioridade e exterioridade.

Porém, o bullying traz consigo uma dificuldade adicional. O relato dos padecentes revela que se trata de um rito de intimidação e subjugação baseado na "lei do mais forte" que se instaura na ausência ou distância do poder mediador do adulto.

Trata-se de uma valentia que se aproveita da micro situação em que a ausência do adulto monta cenário favorável à apropriação emocional e corporal do outro.

Portanto, observar práticas de bullying supõe mais do que adentrar escolas em perspectiva etnográfica, demanda literalmente esconder-se.

Supondo que essa ocultação de si fosse possível, o dilema maior do investigador se apresentaria na sequência. Como assistir sem interromper?

Por isso, o processo de coleta de informações e impressões, salvo em situações muito específicas comumente assistidas por recursos de filmagem, raramente se vale da simultaneidade, operando no mais das vezes com registros posteriores da opinião dos que protagonizaram tais situações.

Em relação às situações em si, algumas características foram seguidamente confirmadas. Tal como os professores perceberam, o bullying não ocorre sem a exposição da vítima a grupos que sustentam a ascendência do praticante sobre o padecente. Ou seja, a representação da plateia faz muito sentido.

Olh@res, Guarulhos, v. 1, n. 2, p. 31-55, Novembro, 2013. 
Essa plateia tem participação decisiva na desorganização emocional da criança padecente. O depoimento de crianças vítimas do bullying revelou que o cotidiano se torna insuportável à medida que se desenvolve a certeza de que determinadas cenas serão repetidas.

A antecipação do sofrimento, ou seja, a certeza de que os atores estarão no local previsto e que o intimidador acionará as mesmas palavras de mobilização da plateia em relação às fragilidades expostas ao ridículo, foi descrita como o aspecto mais destrutivo da experiência.

Nem sempre a subjugação envolve um aluno fisicamente mais forte em relação a outro fisicamente mais fraco. Estabelece-se na maioria das vezes uma assimetria que concentra estímulos ao agente e retira qualquer sustentação ao paciente.

Como são entretecidas as ações e palavras de quem faz com o escárnio de quem assiste, não são poucas as situações em que uma criança fisicamente mais avantajada se submete a outro que "compensa" seu porte menor com a força da ascendência sobre os que promovem aquilo que uma criança chamou de "massacre do riso".

As marcas do corpo são exploradas até conduzir o padecente ao desespero e alguns mencionam que passaram a "odiar suas próprias características"2.

Os depoimentos e as referências aos episódios de hostilidade entre alunos convidam a perguntar se na abordagem do fenômeno por dentro da escola algo dessa internalidade ajudá-la a defini-lo.

\footnotetext{
${ }^{2}$ Insultos são menos frequentes do que as referências ao corpo. "Vesgo", "dentuço" e "gorda" foram palavras que estiveram na origem de processos de sistemática intimidação. Obrigar o "dentuço" a sorrir é um dos rituais de exposição de uma criança a muitas outras.
}

Olh@ res, Guarulhos, v. 1, n. 2, p. 31-55, Novembro, 2013. 
Nesse sentido, um dado revelou-se surpreendente pelas reiteradas vezes em que apareceu. Adolescentes, com variadas formas de descrever, em muitas ocasiões construíram a mesma narrativa.

Referiram-se a episódios de bullying como se "o todo", ou seja, o agressor, o agredido, a plateia compusessem um cenário com uma trama volátil.

Ou seja, tentavam descrever um processo com "agressões lícitas", exemplificando com situações nas quais intimidadores defenderam intimidados de "outros agressores", como que exteriorizando certa noção de "posse", não da pessoa, mas da situação.

Nesse modo de entender, a escola é percebida como espaço facilitador de acontecimentos dessa natureza.

O fato é que essa percepção produzida entre discentes não goza de nenhuma receptividade entre docentes que não hesitam em condenar o bullying tomando por referência representações da civilidade escolar.

Em alguns momentos o conjunto de explicações construído com os depoimentos colhidos fez lembrar a noção de "parentescos por brincadeira", desenvolvido por Radcliffe-Brown, na década de 1930.

É claro que não é possível comparar contextos tão díspares. Mas a lembrança ocorre porque os "parentescos por brincadeira" eram situações em que num dado momento se estabeleciam "desrespeitos lícitos" e se consolidavam "laços entre os que hostilizam e os que são hostilizados" (Cf. Radcliff-Brown, 2013, pág. 85-6).

Mas é difícil acolher essa percepção discente sem reconhecer nela certa naturalização do sofrimento alheio. A constatação de que o padecimento proporcionado pelo bullying gera consequências desastrosas entre crianças e Olh@res, Guarulhos, v. 1, n. 2, p. 31-55, Novembro, 2013. 
adolescentes exige que professores e gestores se disponham a interromper, sempre que necessário, as dinâmicas de intimidação que têm se multiplicado a despeito das dificuldades que se avolumam no sentido de definir, precisar e entender o que tem acontecido.

\section{Considerações finais}

Este artigo procurou demonstrar algumas dificuldades que acompanham a intenção de emitir opinião sobre a relação entre o bullying e o fracasso escolar.

A multiplicação de sentidos atribuídos à palavra; a identificação de situações as mais díspares com o bullying; a apropriação permeada de impressões são fatores que acrescentam dificuldades hermenêuticas.

Considerando isso, a experiência de organizar a compreensão que temos a respeito do problema promovendo uma "escuta ativa" da voz do professorado revelou-se fértil e promissora.

A aproximação em relação às personagens diretamente envolvidas com essas práticas de intimidação revelou o aspecto mais complexo no processo de construção da opinião a respeito.

Qual etnografia é possível em situações semelhantes?

Trata-se de uma questão que só será respondida à medida que outras questões sejam discutidas simultaneamente, entre elas, a importância dos estudos e pesquisas que abordem a escola por dentro.

Este é um texto inconclusivo em muitos aspectos. Porém, é possível afirmar mais incisivamente que os professores consideram sim as práticas de intimidação entre pares, o bullying, uma das faces do fracasso escolar.

Olh@res, Guarulhos, v. 1, n. 2, p. 31-55, Novembro, 2013. 
Do pouco que foi possível apreender, soou recompensador perceber entre os docentes tão pouca disponibilidade a abordar a questão em perspectiva patologizante.

Resta sempre entre nós docentes a expectativa de abordar a escola e os processos de escolarização, suas personagens e seus cenários, como uma trama, não só no sentido que Goffman confere à palavra, mas também no sentido que o tecelão aporta aos fios entremeados no tecido. 


\section{Referências bibliográficas}

BECKER, H.S. Outsiders. Rio de Janeiro, Zahar Editora, 2008.

BONNAFE-SCHMITT, J.P. "La mediation scolaire: une technique de la violence ou un processus éducatif?" In: CHARLOT, B. (org.). Violence à l'école: état des saviors. Paris, Armand Colin, 1997.

DEÁK, C \& SCHIFFER, S.R. O processo de urbanização no Brasil. São Paulo, Edusp, 1999.

DEBARBIEUX, E. “La violence à l'école em France: 30 ans de construction socilae de l'objet (1967-1997)". Paris, Revue Française de Pedagogie, n. 123, 1998.

DUBET, F. \& MARTUCCELLI, D. À l'école: sociologie de l'expérience scolaire. Paris, Seuil, 1996.

DUBET, F. Sociologie de l'experience. Paris, Seuil, 1994

ELIAS, N. Os estabelecidos e os outsiders. Rio de Janeiro, Zahar Editora, 2005.

FREITAS, M.C. O aluno incluído na educação básica: avaliação e permanência. São Paulo, Cortez Editora, 2013.

GINZBURG, C. "O inquisidor como antropólogo: uma analogia e as suas implicações". In: GINZBURG, C. A micro-história e outros ensaios. Lisboa, DIFEL, 1989.

GOFFMAN, E. A representação do eu na vida cotidiana. Petrópolis, Editora Vozes, 2004.

GOFFMAN, E. Estigma: notas sobre a manipulação da identidade deteriorada. Rio de Janeiro, LTC, 1988.

LACLAU, E. Política e ideologia na teoria marxista: capitalismo, fascismo e populismo. Rio de Janeiro, Paz e Terra, 1979.

MARTINS, J.S. "O falso problema da exclusão e o problema social da inclusão marginal". In: MARTINS, J.S. Excusão social e a nova desigualdade. São Paulo, Editora Paulus, 1997, pp. 124-144.

RADCLIFFE-BROWN, A.R. Estrutura e função na sociedade primitiva. Petrópolis, Editora Vozes, 2013.

Olh@res, Guarulhos, v. 1, n. 2, p. 31-55, Novembro, 2013. 
ROSANVALLON, P. "Para uma história conceitual do político." Revista Brasileira de História. São Paulo, ANPUH-Contexto, (15): 9-22, 1995. WHYTE, W.F. Sociedade de esquina. Rio de Janeiro, Zahar Editora, 2008.

WIILliAMS, R. Keywords. New York, Oxford University Press, 2000.

WOODS, P. La escuela por dentro. Barcelona, Paidos, 2000.

XIBERRAS, M. As teorias da exclusão: para uma construção do imaginário do desvio. Lisboa, Instituto Piaget, 1993. 